\title{
Speciation and preconcentration of inorganic tellurium from waters using a mercaptosilica microcolumn and determination by hydride generation atomic absorption spectrometry
}

\author{
Aslıhan Körez, ${ }^{a}$ Ahmet E. Eroğlu, ${ }^{b}$ Mürvet Volkan $^{a}$ and O. Yavuz Ataman ${ }^{a}$ \\ ${ }^{a}$ Department of Chemistry, Middle East Technical University, 06531 Ankara, Turkey. \\ E-mail: ataman@metu.edu.tr \\ ${ }^{b}$ Department of Chemistry, Izmir Institute of Technology, 35437 Urla-İzmir, Turkey
}

Received 13th June 2000, Accepted 18th October 2000

First published as an Advance Article on the web 23rd November 2000

\begin{abstract}
A separation-preconcentration method utilising a mercapto-modified silica microcolumn was developed for the determination of trace amounts of $\mathrm{Te}$ (IV) and $\mathrm{Te}$ (vI) in waters by hydride generation atomic absorption spectrometry. Bottled drinking water, tap water and sea-water samples were spiked with sub-ng $\mathrm{ml}^{-1}$ concentrations of $\mathrm{Te}$ (IV) and the spiked solutions were subjected to the mercapto-modified silica microcolumn separation and enrichment procedure. The spike recovery values varied between 86 and $114 \%$. In addition to spike recovery experiments, accuracy was also verified via the analysis of a certified reference material. The limit of detection for Te(IV) in sea-water with a preconcentration factor of 50 was $0.037 \mathrm{ng} \mathrm{ml}^{-1}$. The capability of the microcolumn enrichment scheme for on-line sample processing via flow manifolds was demonstrated. A detailed interference study was performed.
\end{abstract}

\section{Introduction}

Tellurium is regarded as a rare, non-essential element and is known to be toxic to humans. ${ }^{1}$ It has found many applications in metallurgical processes, glass manufacturing, pharmaceutical processes and also in the rubber and plastics industry. It is also used in electronics as a semiconductor.

Tellurium concentrations in agricultural, geological and environmental samples are usually at trace levels $\left(<\mathrm{ng} \mathrm{l}^{-1}\right),{ }^{2}$ while on some occasions as much as $0.17 \mu \mathrm{g} 1^{-1}$ total Te was observed in sub-marine hydrothermal waters. ${ }^{3}$ Determination of tellurium in almost any environmental sample requires an enrichment step prior to instrumental measurement because of these very low concentrations. The most commonly used separation and enrichment techniques include ion exchange ${ }^{4}$ and chelating materials, ${ }^{5}$ and coprecipitation procedures. ${ }^{3,6,7}$ In many of the methods used for tellurium determination, atomic absorption spectrometry is used such that tellurite is reduced to its hydride using a hydride generation system followed by either atomisation in the flame using heated quartz tubes $^{5,8}$ or in situ trapping in a graphite tube prior to atomisation..$^{6,9,10}$ Developments in hydride generation and in situ trapping techniques in the graphite furnace can be found in ref. 11 and 12. Electrothermal atomic absorption spectrometry (ETAAS) has been employed for Te determination in various samples generally after an enrichment step with solvent extraction. ${ }^{13-15}$ In addition to atomic absorption spectrometry (AAS), other atomic spectrometric techniques, such as inductively coupled plasma-optical emission spectrometry (ICP-OES), ${ }^{16-18}$ and inductively coupled plasma-mass spectrometry (ICP-MS), ${ }^{19-21}$ have been applied to the determination of Te and hydride generation has generally been the method of choice for sample introduction in these studies. Alternative applications using chromatographic, fluorimetric, electrochemical and spectrometric detection systems in the determination of Te have been outlined in ref. 2 .

Use of enrichment techniques, in many cases, also allows the separation of the analyte from the sample matrix, thus minimising interference effects in the final detection step. A notable enrichment and separation method for the determination of arsenic, antimony, selenium and tellurium in water has been suggested by $\mathrm{Yu}$ et $a .^{5}$ The selectivity of thiol cotton towards lower and higher oxidation states of the elements mentioned was used for separation and enrichment. The procedure was successfully employed to determine $\mathrm{ngl}^{-1}$ concentrations of $\mathrm{As}, \mathrm{Sb}, \mathrm{Se}$ and $\mathrm{Te}$ in natural waters. The spike recoveries were in the range $90-110 \%$.

It is generally necessary to determine the concentration of the various oxidation states of tellurium since the behaviour of the element depends on the chemical form and the oxidation state rather than its total concentration.

The aim of this study was to develop a rapid and sensitive enrichment procedure using a microcolumn of mercaptomodified silica for the determination of tellurium in natural waters by hydride generation atomic absorption spectrometry (HGAAS). The heart of the enrichment procedure is the use of mercapto-modified silica, developed by Howard et al.,22 which has been shown to be an efficient separation and preconcentration material for arsenite from samples that also contain arsenate and organoarsenic compounds. The efficiency of the mercapto-silica has also been tested and shown to be successful in the determination of some metals in natural waters. ${ }^{23}$ The second feature of the proposed method is the use of microcolumns of mercapto-silica in the enrichment step. The advantages of using microcolumns in the determination of various species can be found elsewhere ${ }^{24-27}$ they include the use of moderate sample volumes $(5-100 \mathrm{ml})$ rather than applying relatively large amounts of samples ( $>11)$, suitability of methods for field sampling, ease of transportation, preservation of the analyte species in their original forms (matrix isolation, separation) and reduction in both sample size and sampling time. The efficiency of the proposed method was tested by application to a reference material and also through spike recovery experiments.

Another objective of this study was to show the possibility of 
using the proposed methodology in the determination of tellurium species for future on-line preconcentration systems.

\section{Experimental}

\section{Reagents and materials}

Unless stated otherwise all reagents were of analytical reagent grade. Glassware and plastic containers were cleaned by soaking in dilute nitric acid $(1+9)$ and rinsed with distilled water prior to use. Tellurium atomic absorption standard solution supplied by Aldrich (Milwaukee, WI, USA) was used as the tellurite standard solution and tellurate stock solution was prepared from telluric acid, $\mathrm{H}_{2} \mathrm{TeO}_{4} \cdot 2 \mathrm{H}_{2} \mathrm{O}$ (AnalaR Grade; BDH, Poole, Dorsot, UK), by dissolution in de-ionised water. Standards with lower concentrations were prepared, by appropriate dilutions, from stock solutions in $2.0 \mathrm{M} \mathrm{HCl}$ with $18 \mathrm{M} \Omega$ de-ionised water obtained from a Millipore (Bedford, MA, USA) Milli-Q water-purification system. Silica gel (6080 mesh; Merck, Darmstadt, Germany) was used in the preparation of mercapto-modified silica. Sodium tetrahydroborate $\left(\mathrm{NaBH}_{4}\right)$ was a fine-granuled product $(>96 \%$, Merck). PTFE tubing for the preparation of microcolumns was supplied by Alltech Associates/Applied Science (Carnforth, Lancashire, UK).

\section{Instrumentation and apparatus}

An atomic absorption spectrometer, Philips Pye Unicam (Cambridge, UK) PU 9200, with an air-acetylene flame and a $50 \mathrm{~mm}$ burner slot was used in all measurements. A Philips Pye Unicam PU 9390 electrothermal atomisation unit with a GF90 graphite furnace head was employed in the ETAAS measurements. A Unicam Te hollow cathode lamp was operated with a maximum current of $6 \mathrm{~mA}$ and a wavelength of $214.3 \mathrm{~nm}$ was used in the measurements. A deuterium hollow cathode lamp was used for background correction.

A schematic representation of the hydride generation apparatus used is shown in Fig. 1. Plastic centrifuge tubes $(25 \mathrm{ml})$ were used as reaction vessels. Tygon tubing was used in all connections. The reaction vessels containing the acidified standards and samples were placed over the lifting platform. A gas-tight connection was provided between the reaction vessel and the rubber stopper holding a Y-shaped glass tube which was used for introduction of nitrogen and injection of $\mathrm{NaBH}_{4}$ solution via a plastic injector through a gas-tight rubber septum. The carrier gas stream and the hydrogen telluride formed on injection of the $\mathrm{NaBH}_{4}$ solution were transferred to a quartz T-tube $(12 \mathrm{~cm} \times 8 \mathrm{~mm}$ id) placed over the air-acetylene burner head.

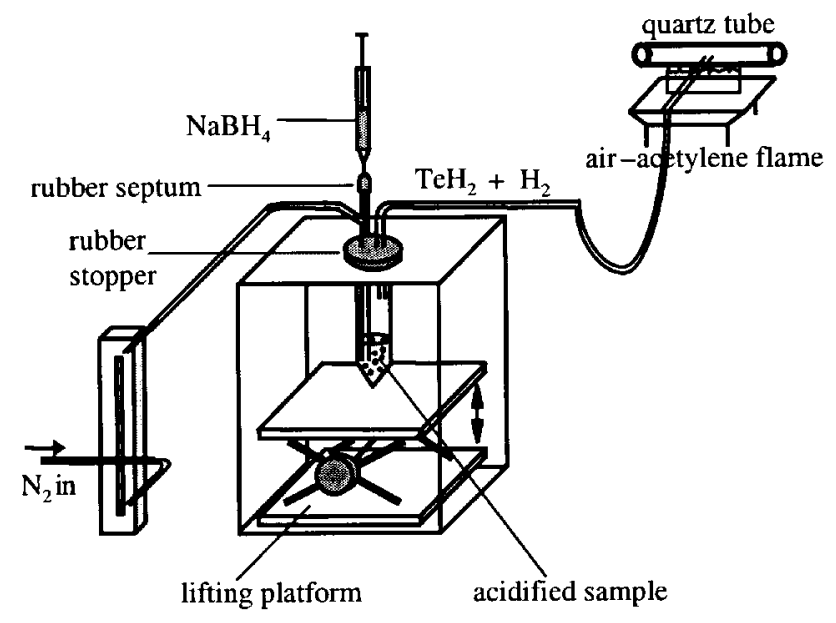

Fig. 1 Schematic illustration of the hydride generation apparatus.

\section{Preparation of mercapto-modified silica microcolumns}

Mercapto-modified silica was prepared by mixing silica gel with 3-mercaptopropyltrimethoxysilane under controlled conditions. Five grams of silica gel $(60-80 \mathrm{mesh}$, Merck) were washed with $100 \mathrm{ml}$ of acetic acid $(0.01 \mathrm{M})$ under vacuum for $10 \mathrm{~min}$. Silica gel particles were then filtered through a pump and transferred to a flask containing $25 \mathrm{ml}$ of toluene. With vigorous magnetic stirring, $3.0 \mathrm{ml}$ of 3-mercaptopropyltrimethoxysilane (Alfa Products, Ward Hill, MA, USA) were added slowly to prevent self-polymerisation. Then, $0.15 \mathrm{ml}$ of concentrated acetic acid was added dropwise and the mixture was stirred overnight. Before refluxing the mixture at $60^{\circ} \mathrm{C}$ for $2 \mathrm{~h}$ with magnetic stirring, another $0.15 \mathrm{ml}$ portion of acetic acid was added. Finally, silica gel particles were filtered using a vacuum pump and washed well with toluene before being left overnight in an oven at $80^{\circ} \mathrm{C}$. Mercapto-modified silica, thus prepared, was used as the packing material in the preparation of microcolumns. The mercaptosilica particles, having sizes between 100 and $150 \mu \mathrm{m}$, were packed into $4 \mathrm{~cm}$ PTFE tubing ( $3 \mathrm{~cm}$ active length, $1 \mathrm{~mm}$ id); pieces of sponge at both ends were used to keep the packing material tightly packed. The sponge size was minimal so as not to cause any column backpressure.

\section{Operating procedures}

Use of microcolumn and HGAAS measurements. Sample solutions were passed through the microcolumns at a flow rate of $3.0 \mathrm{ml} \mathrm{min}-1$ for the deposition of the analyte, using a peristaltic pump (Gilson Minipuls 3, Villiers-le-Bel, France). Potassium iodate solution $\left(0.025 \mathrm{M} \mathrm{KIO}_{3}\right.$ in $\left.2.0 \mathrm{M} \mathrm{HCl}\right)$ was used as the eluent at a flow rate of $1.0 \mathrm{ml} \mathrm{min}{ }^{-1}$. For each measurement, $1.0 \mathrm{ml}$ of the eluate was placed in the reaction vessel of the hydride generation system and hydrogen telluride generated by the injection of $1.0 \mathrm{ml}$ of $1 \% \mathrm{~m} / \mathrm{v} \mathrm{NaBH} 4$ was sent to the atomiser and measured. Operating parameters for the microcolumn-HGAAS system are given in Table 1.

Interference studies. The general sequence of experiments followed in interference studies is outlined in Fig. 2. A $100.0 \mathrm{ml}$ solution containing $1.0 \mathrm{ng} \mathrm{ml}^{-1}$ tellurite and the interferent metal ion at a selected concentration was prepared in deionised water and loaded onto the mercaptosilica microcolumn with a flow rate of $3.0 \mathrm{ml} \mathrm{min}{ }^{-1}$ (STEP A). The effluent was discarded. The microcolumn was then eluted with $5.0 \mathrm{ml}$ of the eluent $\left(0.025 \mathrm{M} \mathrm{KIO}_{3}\right.$ in $\left.2.0 \mathrm{M} \mathrm{HCl}\right)$ at a flow rate of $1.0 \mathrm{ml} \mathrm{min}{ }^{-1}$ (STEP B). Therefore, a Te concentration of $20.0 \mathrm{ng} \mathrm{ml}^{-1}$ was expected to be measured at the end of the procedure if the recovery was $100 \%$. A $3.0 \mathrm{ml}$ aliquot of the eluate (ROUTE 1) was analysed by HGAAS (STEP C) and the percentage recovery of the microcolumn methodology was calculated from the Te concentration found. If the recovery of Te was found to be $100 \pm 10 \%$, it was concluded that the element of interest did not cause any interference on the $\mathrm{Te}$

Table 1 Operating parameters

\begin{tabular}{|c|c|}
\hline \multicolumn{2}{|l|}{$H G A A S-$} \\
\hline Carrier gas $\left(\mathrm{N}_{2}\right)$ flow rate & $2.01 \mathrm{~min}^{-1}$ \\
\hline Sample volume & $1.0 \mathrm{ml}$ \\
\hline $\mathrm{HCl}$ concentration & $2.0 \mathrm{M}$ \\
\hline $\mathrm{NaBH}_{4}$ concentration $^{a}$ & $\begin{array}{l}1 \% \mathrm{~m} / \mathrm{v} \text { (aqueous calibration) } \\
2 \% \mathrm{~m} / \mathrm{v} \text { (for } \mathrm{KIO}_{3} \text { solutions) }\end{array}$ \\
\hline $\mathrm{NaBH}_{4}$ volume injected & $1.0 \mathrm{ml}$ \\
\hline \multicolumn{2}{|l|}{ Microcolumn preconcentration- } \\
\hline Length of column & $3 \mathrm{~cm}$ \\
\hline Deposition flow rate & $3.0 \mathrm{ml} \mathrm{min}-1$ \\
\hline Elution flow rate & $1.0 \mathrm{ml} \mathrm{min}^{-1}$ \\
\hline Eluent & $0.025 \mathrm{M} \mathrm{KIO}_{3}$ in $2.0 \mathrm{M} \mathrm{HCl}$ \\
\hline
\end{tabular}




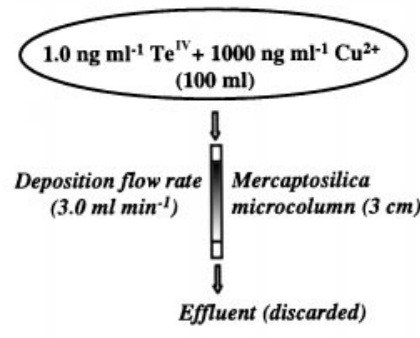

STEP A

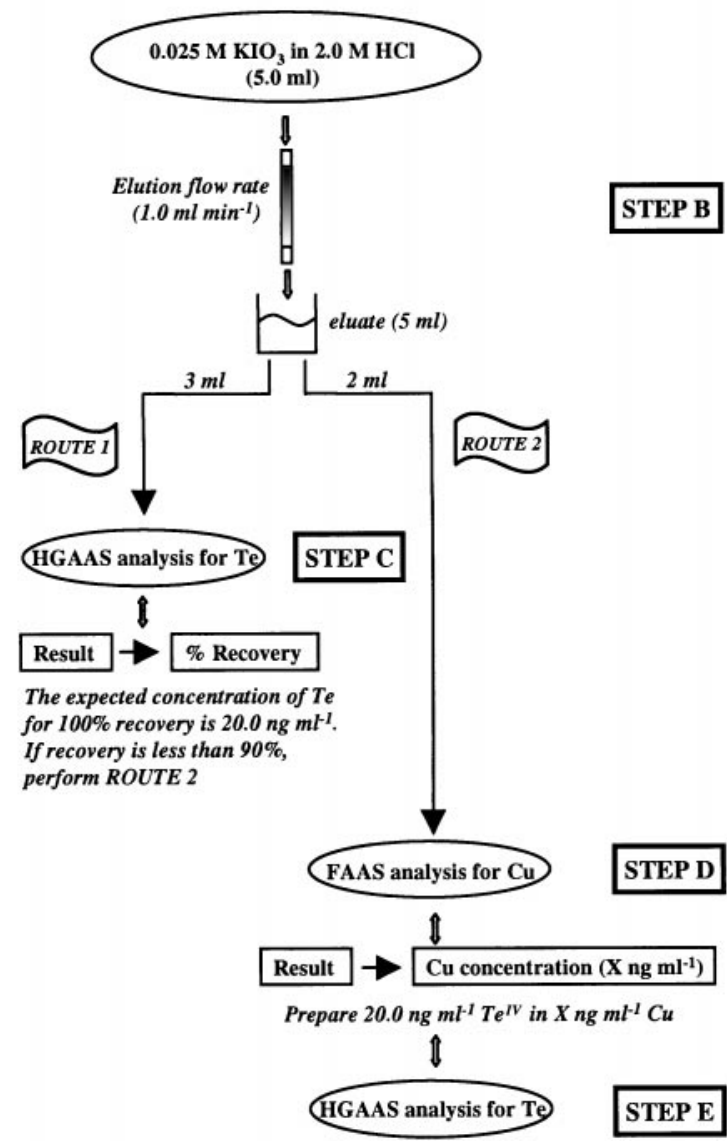

Fig. 2 Strategy followed in the interference studies $\left(\mathrm{Cu}^{2+}\right.$ was chosen as an example).

signal under these conditions. If the recovery was less than $90 \%$, the remaining $2.0 \mathrm{ml}$ of the eluate (ROUTE 2) were analysed by flame AAS (STEP D) to determine the concentration of the interferent. A Te concentration of $20.0 \mathrm{ng} \mathrm{ml}^{-1}$ was prepared in the eluent $\left(0.025 \mathrm{M} \mathrm{KIO}_{3}\right.$ in $\left.2.0 \mathrm{M} \mathrm{HCl}\right)$ containing also the interferent whose concentration was the same as that found in the eluate (STEP D). The Te signal of this solution measured with HGAAS (STEP E) was compared with the Te signal obtained from a $20.0 \mathrm{ng} \mathrm{ml}^{-1}$ tellurite standard prepared in the eluent $\left(0.025 \mathrm{M} \mathrm{KIO}_{3}\right.$ in $\left.2.0 \mathrm{M} \mathrm{HCl}\right)$. If the two signals were the same, indicating that the presence of the interferent did not have any effect on hydride formation, it was concluded that the low recovery was a consequence of the mercaptosilica microcolumn working inefficiently (available active sites on the surface had been occupied by the interferent species). When a reduction in the HGAAS signal of Te in the presence of the interferent (STEP E) was observed as compared with the Te signal obtained from the standard Te solution, it was difficult to be sure about the source of the interference, and the magnitude of the signal reduction was helpful in the decision.

Method validation and spike recovery experiments. A certified reference material (CRM), Trace Metals in Drinking
Waters (Cat. No. CRM TMDW, Lot \# 818921) supplied by High-Purity Standards (Charleston, SC, USA), was employed for method validation. A $10.0 \mathrm{ml}$ aliquot of this solution was loaded onto the mercaptosilica microcolumn at a flow rate of $3.0 \mathrm{ml} \mathrm{min}{ }^{-1}$. After washing the column with $1.0 \mathrm{ml}$ of highpurity water, the species retained by the microcolumn were eluted with $5.0 \mathrm{ml}$ of the eluent $\left(0.025 \mathrm{M} \mathrm{KIO}_{3}\right.$ in $\left.2.0 \mathrm{M} \mathrm{HCl}\right)$ at a flow rate of $1.0 \mathrm{ml} \mathrm{min}{ }^{-1}$. The eluate was analysed by HGAAS for its Te concentration.

Three different water samples were used for recovery tests: bottled drinking water, tap water and sea-water. Aliquots of $100.0 \mathrm{ml}$ from each of the water samples were spiked with $1.0 \mathrm{ng} \mathrm{ml}^{-1}$ tellurite and applied to separate microcolumns of mercaptosilica. After loading the analyte, each microcolumn was washed with high-purity water and then eluted with $5.0 \mathrm{ml}$ of eluent. The concentration of Te in each of the eluents was determined by HGAAS and the percentage spike recovery in each sample was calculated. Similar experiments were repeated with a lower concentration of Te(Iv) spike and a larger volume. This time, $250.0 \mathrm{ml}$ aliquots of water samples were spiked with $0.1 \mathrm{ng} \mathrm{ml}^{-1} \mathrm{Te}(\mathrm{Iv})$ and the enrichment procedure was applied to each sample as described previously.

\section{Results and discussion}

The first part of this work was concentrated on the optimisation of measurement conditions for tellurium determination with the HGAAS system. The second part was concerned with the assessment of the performance of mercaptosilica towards tellurium species, namely tellurite and tellurate. Microcolumns packed with mercaptosilica were used for separation and enrichment of tellurite species from sample matrices. In addition, the possibility of the determination of tellurate after its conversion to tellurite was investigated. The final part was the application of the proposed methodology to a certified reference material to test the efficiency of microcolumn preconcentration. A detailed interference study was also performed in order to make a better evaluation of the method.

\section{Optimisation of HGAAS measurements}

Hydride generation methods have been widely used in atomic spectrometry due to their simplicity, high sensitivity and speciation capability. The technique has also been used in the determination of tellurium in environmental samples, $5,6,9,17$ usually after a suitable preconcentration step. Although the necessary conditions for Te determination have been studied extensively in these applications, initial studies in the present work concentrated on the optimisation of HGAAS measurements since a different enrichment procedure and different chemicals were used. The first parameter was the acidity of the sample since hydride generation strongly depends on the acid concentration. Among various acids, $\mathrm{HCl}$ has been almost universally accepted and therefore it was used throughout this

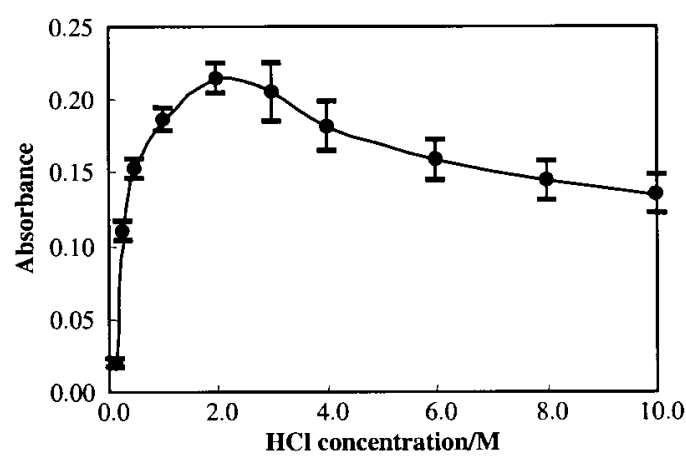

Fig. 3 Change in HGAAS signal of $20.0 \mathrm{ng} \mathrm{ml}^{-1}$ tellurite as a function of $\mathrm{HCl}$ concentration ( $1.0 \mathrm{ml}$ of $1 \% \mathrm{~m} / \mathrm{v} \mathrm{NaBH}$ solution was used). 
Table 2 HGAAS performance data

Calibration response curve ${ }^{a}$ Calibration response curve ${ }^{b}$ Limit of detection

Relative standard deviation ${ }^{d}$ $y=0.0237+0.0088 x(r=0.9995)$ $y=0.0306+0.0091 x(r=0.9905)$ $1.83 \mathrm{ng} \mathrm{ml}^{-1}$ $5.1 \%\left(5.0 \mathrm{ng} \mathrm{ml}^{-1}\right)$ $1.8 \%\left(40.0 \mathrm{ng} \mathrm{ml}^{-1}\right)$

${ }^{a}$ For aqueous calibration (standard solutions in $2.0 \mathrm{M} \mathrm{HCl} ; 1.0 \mathrm{ml}$ of $1 \% \mathrm{~m} / \mathrm{v} \mathrm{NaBH} 4$ used). ${ }^{b}$ For Te species eluted from the microcolumn (in $0.025 \mathrm{M} \mathrm{KIO}_{3}$ and $2.0 \mathrm{M} \mathrm{HCl} ; 1.0 \mathrm{ml}$ of $2 \% \mathrm{~m} / \mathrm{v} \mathrm{NaBH} 4$ used). ${ }^{c}$ Based on $3 s$, without preconcentration. ${ }^{d} n=3$.

study. The change in absorbance signal of $20.0 \mathrm{ng} \mathrm{ml}^{-1}$ tellurite as a function of $\mathrm{HCl}$ concentration is shown in Fig. 3. As can be seen, $2.0 \mathrm{M} \mathrm{HCl}$ gave the best signal and this concentration was used throughout unless stated otherwise. This value is in accordance with the acidity employed in many of the studies in the literature. ${ }^{5,6}$ The use of higher acid concentrations has been suggested by some workers to lower the extent of interference due to an increase in the solubility of the reduced metal species. ${ }^{28,29}$ In addition to the reduction of interferences at high concentrations of $\mathrm{HCl}$, in this study it was especially important to ascertain whether a sensitive measurement could be performed in $6.0 \mathrm{M} \mathrm{HCl}$ since the sample solution was treated with an equal amount of concentrated $\mathrm{HCl}$ for $\mathrm{Te}(\mathrm{vI}) \rightarrow \mathrm{Te}$ (Iv) conversion. During the experiments, it was observed that the reduction was accomplished without any apparent problems. As can be seen in Fig. 3, the sensitivity obtained in the range $0.5-10.0 \mathrm{M} \mathrm{HCl}$ is satisfactory. This finding demonstrated that the samples and standards could be prepared in $6.0 \mathrm{M} \mathrm{HCl}$ without a significant loss of sensitivity. The other parameters such as percentage and volume of $\mathrm{NaBH}_{4}$ solution, carrier gas $\left(\mathrm{N}_{2}\right)$ flow rate, and sample volume were also optimised. The optimum values are given in Table 1 and the HGAAS performance data are given in Table 2. With the optimised conditions, the calibration plot was linear up to $50.0 \mathrm{ng} \mathrm{ml}^{-1}$ tellurite and the $3 \mathrm{~s}$ detection limit of the system without preconcentration was $1.83 \mathrm{ng} \mathrm{ml}^{-1}$. Moreover, there was a linear increase in absorbance with increase in the sample volume which was varied between 0.5 and $3.0 \mathrm{ml}$; a sample volume of $1.0 \mathrm{ml}$ was used in all measurements.

\section{Performance of mercaptosilica towards Te(Iv) and Te(vI) species}

Uptake of mercaptosilica as a function of $\mathrm{pH}$ and $\mathrm{HCl}$ concentration. The suitability of mercaptosilica to enrich As, ${ }^{22}$ $\mathrm{Se}^{30}$ and $\mathrm{Ge}^{31}$ has been shown previously. Knowing that mercaptosilica is selective for the lower oxidation states of the species, namely arsenite and selenite, the initial studies were concerned with the assessment of the behaviour of the material towards tellurite and tellurate species. For this purpose, standard solutions of $30.0 \mathrm{ng} \mathrm{ml}^{-1}$ each of $\mathrm{Te}(\mathrm{IV})$ and $\mathrm{Te}(\mathrm{VI})$ were prepared in various concentrations of $\mathrm{HCl}$ and $\mathrm{pH}$ buffer solutions. Five millilitre aliquots of the standards were passed through separate columns and the collected effluents were analysed by HGAAS. For Te(vI), the eluted solution was mixed

Table 3 Recovery results for $\mathrm{Te}(\mathrm{Iv})$ and $\mathrm{Te}(\mathrm{vI})^{a}$

\begin{tabular}{lllll}
\hline $\begin{array}{l}\text { Te(Iv) added/ } \\
\mathrm{ng} \mathrm{ml}^{-1}\end{array}$ & $\begin{array}{l}\text { Te(vI) added/ } \\
\mathrm{ng} \mathrm{ml}^{-1}\end{array}$ & $\begin{array}{l}\text { Sample pre- } \\
\text { treatment }^{b}\end{array}$ & $\begin{array}{l}\text { Te found/ } \\
\mathrm{ng} \mathrm{ml}^{-1}\end{array}$ & $\begin{array}{l}\text { Recovery } \\
\%\end{array}$ \\
\hline 30.0 & - & No & $29.5 \pm 0.7$ & $98 \pm 2$ \\
- & 30.0 & No & 0 & 0 \\
- & 30.0 & Yes & $29.8 \pm 3.2$ & $99 \pm 11$ \\
30.0 & 30.0 & No & $30.5 \pm 2.1$ & $102 \pm 7$ \\
30.0 & 30.0 & Yes & $57.6 \pm 6.6$ & $96 \pm 11$
\end{tabular}

${ }^{a}$ Sample and eluent volumes were $5.0 \mathrm{ml}$; results are given as (mean value \pm standard deviation); $n=3$. ${ }^{b}$ Sample solution $(5.0 \mathrm{ml})$ was mixed with concentrated $\mathrm{HCl}(5.0 \mathrm{ml})$ and boiled for $10 \mathrm{~min}$ for $\mathrm{Te}(\mathrm{vI}) \rightarrow \mathrm{Te}(\mathrm{IV})$ conversion.

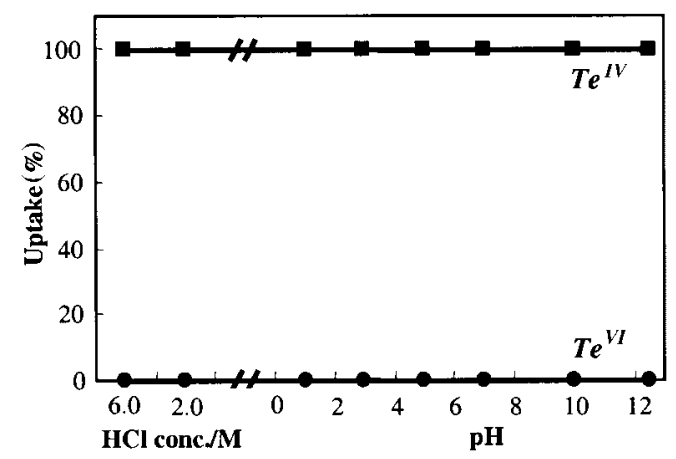

Fig. 4 Percentage uptake of mercapto-modified silica for Te(IV) and $\mathrm{Te}(\mathrm{vI})$ as a function of $\mathrm{pH}$ and $\mathrm{HCl}$ concentration. (口) Te(Iv) ( $\mathrm{Te}(\mathrm{vI})$. The values for Te(Iv) have a $2-5 \% \mathrm{RSD}$; those for Te(vI) were below the detection limit.

with an equal amount of concentrated $\mathrm{HCl}$ and boiled for 10 min to reduce $\mathrm{Te}(\mathrm{vI})$ to $\mathrm{Te}(\mathrm{IV})$, since only the latter can be reduced to hydrogen telluride by $\mathrm{NaBH}_{4}$. The percentage uptake of mercaptosilica towards $\mathrm{Te}(\mathrm{IV})$ and $\mathrm{Te}(\mathrm{vI})$ as a function of $\mathrm{pH}$ and $\mathrm{HCl}$ concentration is shown in Fig. 4. As can be seen, the uptake of neither species is $\mathrm{pH}$ - or aciditydependent in the range of $6.0 \mathrm{M} \mathrm{HCl}$ to $\mathrm{pH} 12.5$. Tellurite is taken up by mercaptosilica at all $\mathrm{pH}$ and acidity values whereas tellurate is not taken up at any $\mathrm{pH}$ or acidity. However, the determination of $\mathrm{Te}(\mathrm{vI})$ by the proposed methodology is possible after a pre-reduction step. The sensitivity of the HGAAS technique for $\mathrm{Te}(\mathrm{vI})$ is actually reduced 2-fold since all the samples should be diluted $1+1$ using concentrated $\mathrm{HCl}$ to give a final solution of $6 \mathrm{M} \mathrm{HCl}$. The recovery results for Te(Iv) and $\mathrm{Te}(\mathrm{vI})$ solutions are summarised in Table 3 . The data presented in Table 3 demonstrate that speciation analysis for $\mathrm{Te}(\mathrm{Iv})$ and $\mathrm{Te}(\mathrm{vI})$ is possible using the analytical method described.

Elution studies. In the search for a suitable eluent, two different strategies were tried to elute the collected species from the mercaptosilica microcolumn which was loaded with $5.0 \mathrm{ml}$ of $40.0 \mathrm{ng} \mathrm{ml}^{-1}$ tellurite: the first approach was to try to find a suitable complexing agent that was capable of removing the adsorbed species from mercaptosilica. Various complexing agents, namely $\mathrm{HBr}(1.0-3.0 \mathrm{M}), \mathrm{KBr}(0.02-0.08 \mathrm{M}), \mathrm{KI}(0.01-$ $0.06 \mathrm{M}), \mathrm{KF}(0.03-0.17 \mathrm{M})$, EDTA $(0.005-0.03 \mathrm{M})$ and $\mathrm{I}_{2}$ $(0.008-0.04 \mathrm{M})$ were tried with a volume of $2.0 \mathrm{ml}$. None was successful in removing Te from mercaptosilica although these materials are accepted as good complexing agents for $\mathrm{Te}$ species in solution. The second approach was to oxidise the $\mathrm{Te}(\mathrm{Iv})$ species adsorbed and to convert them to $\mathrm{Te}(\mathrm{vI})$ which is not adsorbed by the mercaptosilica. Among the various oxidising agents, namely $\mathrm{Ba}\left(\mathrm{ClO}_{4}\right)_{2}(0.005-0.03 \mathrm{M}), \mathrm{KMnO}_{4}$ (0.01-0.06 M), $\mathrm{HNO}_{3}\left(1.0-3.0 \mathrm{M}\right.$, conc.), $\mathrm{HClO}_{4}(1.0-3.0 \mathrm{M}$, conc.), $\mathrm{H}_{2} \mathrm{O}_{2}$ (1.0-3.0 M, conc.), $\mathrm{KIO}_{3}(0.01-0.05 \mathrm{M})$ and $\mathrm{K}_{2} \mathrm{Cr}_{2} \mathrm{O}_{7}(0.01-0.04 \mathrm{M})$; concentrated $\mathrm{H}_{2} \mathrm{O}_{2}$ was found to elute about $50 \%$ of $\mathrm{Te}$ retained by the microcolumn. Potassium dichromate $\left(0.01 \mathrm{M} \mathrm{K}_{2} \mathrm{Cr}_{2} \mathrm{O}_{7}\right.$ in $\left.2.0 \mathrm{M} \mathrm{HCl}\right)$ removed retained Te from the microcolumn quantitatively. The disadvantage of using this eluent was that it was necessary to use a prereduction step on the eluate prior to instrumental measurement to convert the previously oxidised Te species to the Te(Iv) form. This pre-reduction step is time consuming and also causes a 2fold dilution with the addition of concentrated $\mathrm{HCl}$ and this is a drawback, especially in an enrichment study of this type.

The solution to this problem was to use another strong oxidant, $\mathrm{KIO}_{3}$. The retained $\mathrm{Te}$ species were quantitatively desorbed from the microcolumn using $2.0 \mathrm{ml}$ of $0.025 \mathrm{M} \mathrm{KIO}_{3}$ in $2.0 \mathrm{M} \mathrm{HCl}$. Potassium iodate eluted Te species from the column very efficiently; in addition, it was possible to quantify $\mathrm{Te}$ in $\mathrm{KIO}_{3}$ solution directly. In other words, the HGAAS 
signal was efficiently obtained without any need for prereduction. Therefore, it was concluded that $\mathrm{KIO}_{3}$ was able to elute the analyte in the Te(Iv) form. Since there was apparently no oxidation of the analyte, it is possible that potassium iodate was destroying the mercaptosilica by oxidising the $\mathrm{SH}$ functional groups and thus releasing the analyte species. This situation restricts the use of microcolumns to a single loading only; however, since a relatively small amount of mercaptosilica, approximately $0.02 \mathrm{~g}$, is used in a microcolumn, the related cost is not significant. Owing to the presence of excess of $\mathrm{KIO}_{3}$, an oxidant, the only difference was the use of twice the concentration of $\mathrm{NaBH}_{4}$ as that used for aqueous solutions; during the construction of the calibration plot, $1.0 \mathrm{ml}$ of $1.0 \%$ $\mathrm{m} / \mathrm{v} \mathrm{NaBH}_{4}$ solution was used whereas $1.0 \mathrm{ml}$ of $2.0 \% \mathrm{~m} / \mathrm{v}$ reductant was employed for Te species after the elution step because of the oxidising nature of $\mathrm{KIO}_{3}$. The linear regression equations for calibration plots for $\mathrm{Te}(\mathrm{IV})$ concentrations ranging from 2.5 to $40.0 \mathrm{ng} \mathrm{ml}^{-1}$ in $2.0 \mathrm{M} \mathrm{HCl}$ and for the eluted Te species (in $0.025 \mathrm{M} \mathrm{KIO}_{3}, 2.0 \mathrm{M} \mathrm{HCl}$ ) are given in Table 2. Slopes and therefore calibration sensitivities are quite similar for these calibration plots.

It was also found that, depending on the sample volume, flow rates varying between 1.0 and $5.0 \mathrm{ml} \mathrm{min}^{-1}$ can be used during deposition without any recovery loss as the kinetics of the reaction between mercaptosilica and Te(IV) species is very fast; however, $3.0 \mathrm{ml} \mathrm{min}^{-1}$ was selected as the optimum. A flow rate of $1.0 \mathrm{ml} \mathrm{min}{ }^{-1}$ was applied for elution to allow sufficient time for the eluent to effect a complete removal.

Tellurite capacity of mercaptosilica. The capacity of mercaptosilica for Te(IV) was assessed by passing known concentrations of the species through a fixed amount of mercaptosilica packed in a microcolumn. A solution containing $1.0 \mathrm{mg} \mathrm{l}^{-1}$ $\mathrm{Te}(\mathrm{Iv})$ was passed through a microcolumn $(0.02 \mathrm{~g}$ mercaptosilica) at a flow rate of $3.0 \mathrm{ml} \mathrm{min}-1$. The effluent was analysed for Te at several stages of loading. It was observed that a maximum of $130 \mu \mathrm{g}$ of $\mathrm{Te}$ (Iv) could be loaded onto the microcolumn. After this point, the effluent contained detectable Te. These results correspond to a column capacity of $6.5 \mathrm{mg} \mathrm{Te}(\mathrm{Iv})$ per gram of mercaptosilica.

A similar experiment was also performed using bare silica instead of mercapto-modified silica to see whether any uptake was taking place. It was found that bare silica does not retain $\mathrm{Te}(\mathrm{IV})$ species under the specified conditions. Hence, it was concluded that all uptake was due to mercapto active sites.

\section{Interference studies}

A detailed study was carried out to examine the effect of possible interferences in Te determination and preconcentration. Both hydride-forming elements and some transition metals were selected as potential interferents. Hydride-forming elements were expected to cause a suppression effect on the tellurium signal for two reasons: firstly, they are also retained by mercaptosilica, ${ }^{22,30,31}$ possibly lowering its efficiency; and secondly, they may cause gas phase interferences in the atomiser due to either consumption of hydrogen radicals by accelerating their decay or causing analyte atoms to decay faster, thereby leaving fewer free atoms in the optical path. ${ }^{32}$ In addition to hydride-forming elements, interference effects of some transition metals were also tested since the presence of some metal ions in the sample has been shown to cause both liquid phase and gas phase interferences in the determination of hydride-forming elements by AAS. ${ }^{29}$ Furthermore, it has previously been shown that mercaptosilica removes divalent cations of $\mathrm{Cd}, \mathrm{Cu}, \mathrm{Pb}$ and $\mathrm{Zn}$ from aqueous solutions. ${ }^{23}$ Therefore, it was assumed that if the sample contained any of these metals, they would be retained by the mercaptosilica. In addition, some of the retained metals could also be eluted from the microcolumn since $2.0 \mathrm{M} \mathrm{HCl}$ was shown to elute approximately $55 \%$ of the retained metals ${ }^{23}$ and $0.025 \mathrm{M}$ $\mathrm{KIO}_{3}$ in $2.0 \mathrm{M} \mathrm{HCl}$ was used for the elution of Te species.

For these reasons, it was decided to perform a detailed interference study in order to differentiate between the interference caused by the reduction in efficiency of the mercaptosilica microcolumn to retain $\mathrm{Te}$ species from the solution, and the liquid and/or gas phase interferences caused by the other volatile hydrides and metal ions in the hydride generation step. The results obtained from the interference study are summarised in Table 4 . The term "interference" stands for a negative interference in all cases.

As can be seen from Table 4, arsenite and germanate cause no interference either in the microcolumn preconcentration step or during hydride generation at any concentrations of the interferent whereas selenite, $\mathrm{Ag}^{+}$and $\mathrm{Cu}^{2+}$ show both types of interference at all concentrations investigated.

For $\mathrm{In}^{3+}, \mathrm{Fe}^{3+}$ and $\mathrm{Pb}^{2+}$, no interference is observed in the hydride generation step at any concentration. However, when their concentrations are $1000 \mathrm{ng} \mathrm{ml}^{-1}$ (1000 times the concentration of Te in the solution), they cause interference in the preconcentration step. This was the case for almost all the interferents investigated; if the concentration of any species which is also retained by the mercaptosilica increases beyond the capacity of the microcolumn, the mercapto active sites are occupied by the interferent species in addition to tellurite; therefore, some of the tellurite leaves the microcolumn without

Table 4 Summary of interference studies ${ }^{a}$

\begin{tabular}{|c|c|c|c|c|c|c|}
\hline \multirow[b]{2}{*}{ Element } & \multicolumn{2}{|c|}{$1000 \mathrm{ng} \mathrm{ml}^{-1}$} & \multicolumn{2}{|c|}{$500 \mathrm{ng} \mathrm{ml}^{-1}$} & \multicolumn{2}{|c|}{$100 \mathrm{ng} \mathrm{ml}^{-1}$} \\
\hline & Column & Hydride & Column & Hydride & Column & Hydride \\
\hline Arsenite & $\mathrm{N}$ & $\mathrm{N}$ & $\mathrm{N}$ & $\mathrm{N}$ & $\mathrm{NE}$ & $\mathrm{NE}$ \\
\hline Germanate & $\mathrm{N}$ & $\mathrm{N}$ & $\mathrm{N}$ & $\mathrm{N}$ & $\mathrm{NE}$ & $\mathrm{NE}$ \\
\hline Selenite & I & I & I & I & I & I \\
\hline $\mathrm{Sn}^{2+}$ & I & $\mathrm{N}$ & I & $\mathrm{N}$ & I & $\mathrm{N}$ \\
\hline $\mathrm{Sb}(\mathrm{III})$ & I & I & I & I & $\mathrm{N}$ & $\mathrm{N}$ \\
\hline $\operatorname{In}^{3+}$ & I & $\mathrm{N}$ & $\mathrm{N}$ & $\mathrm{N}$ & NE & $\mathrm{NE}$ \\
\hline $\mathrm{Pb}^{2+}$ & I & $\mathrm{N}$ & $\mathrm{N}$ & $\mathrm{N}$ & $\mathrm{NE}$ & $\mathrm{NE}$ \\
\hline Bi(III) & I & NR & I & NR & I & NR \\
\hline $\mathrm{Fe}^{3+}$ & I & $\mathrm{N}$ & $\mathrm{N}$ & $\mathrm{N}$ & $\mathrm{N}$ & $\mathrm{N}$ \\
\hline $\mathrm{Cd}^{2+}$ & I & $\mathrm{N}$ & I & $\mathrm{N}$ & $\mathrm{N}$ & $\mathrm{N}$ \\
\hline $\mathrm{Co}^{2+}$ & I & $\mathrm{N}$ & I & $\mathrm{N}$ & I & $\mathrm{N}$ \\
\hline $\mathrm{Ni}^{2+}$ & I & I & I & $\mathrm{N}$ & I & $\mathrm{N}$ \\
\hline $\mathrm{Zn}^{2+}$ & I & $\mathrm{N}$ & I & $\mathrm{N}$ & I & $\mathrm{N}$ \\
\hline $\mathrm{Cu}^{2+}$ & I & I & I & I & I & I \\
\hline $\mathrm{Ag}^{+}$ & I & I & $\mathrm{I}$ & I & I & $\mathrm{I}$ \\
\hline \multicolumn{7}{|c|}{$\begin{array}{l}{ }^{a} 100.0 \mathrm{ml} \text { of } 1.0 \mathrm{ng} \mathrm{ml}^{-1} \mathrm{Te}(\mathrm{IV}) \text { containing interferent species were } \\
\text { loaded onto mercaptosilica microcolumns and after elution with } \\
0.025 \mathrm{M} \mathrm{KIO}_{3} \text { in } 2.0 \mathrm{M} \mathrm{HCl} \text {, the eluents were analysed for their Te } \\
\text { concentration. I: Interferes (causes more than } 10 \% \text { suppression of } \\
\text { analyte signal); N: no interfererence; NE: not examined; NR: no } \\
\text { result. }\end{array}$} \\
\hline
\end{tabular}

Table 5 Composition of the certified drinking water sample used ${ }^{a}$

\begin{tabular}{lrlrlr}
\hline Element & $\begin{array}{c}\text { Concen- } \\
\text { tration }\end{array}$ & Element & $\begin{array}{c}\text { Concen- } \\
\text { tration }\end{array}$ & Element & $\begin{array}{c}\text { Concen- } \\
\text { tration }\end{array}$ \\
\hline Aluminium & 120 & Copper & 20 & Selenium & 10 \\
Antimony & 10 & Iron & 100 & Silver & 2 \\
Arsenic & 80 & Lead & 40 & Sodium & 6000 \\
Barium & 50 & Lithium & 20 & Strontium & 250 \\
Beryllium & 20 & Magnesium & 9000 & Tellurium & 3 \\
Bismuth & 10 & Manganese & 40 & Thallium & 10 \\
Cadmium & 10 & Molybdenum & 100 & Vanadium & 30 \\
Calcium & 35000 & Nickel & 60 & Uranium & 10 \\
Chromium & 20 & Potassium & 2500 & Zinc & 70 \\
Cobalt & 25 & Rubidium & 10 & &
\end{tabular}

${ }^{a}$ Trace Metals in Drinking Waters, Cat. No. CRM TMDW, Lot \# 818921, High-Purity Standards, Charleston, SC, USA (concentrations $=\mathrm{ng} \mathrm{ml}^{-1} \pm 0.5 \%$ ). 


\begin{tabular}{|c|c|c|c|c|}
\hline & $\begin{array}{l}\text { Te(IV) spike } \\
\text { concentration/ } \\
\mathrm{ng} \mathrm{ml}^{-1}\end{array}$ & $\begin{array}{l}\text { Te(Iv) concentration } \\
\text { determined by } \\
\text { HGAAS/ng ml }\end{array}$ & $\begin{array}{l}\text { Te(IV) concentration } \\
\text { determined by ETAAS/ } \\
\mathrm{ng} \mathrm{ml}^{-1}\end{array}$ & $\begin{array}{l}\text { Recovery } \\
\%\end{array}$ \\
\hline Bottled drinking water & $1.00^{b}$ & $0.97 \pm 0.06$ & $0.95 \pm 0.06$ & $96 \pm 6$ \\
\hline Tap water & $1.00^{b}$ & $0.98 \pm 0.12$ & $0.98 \pm 0.08$ & $98 \pm 12$ \\
\hline Sea-water & $1.00^{b}$ & $0.99 \pm 0.02$ & $0.105 \pm 0.02$ & $99 \pm 2$ \\
\hline Bottled drinking water & $0.100^{c}$ & $0.100 \pm 0.012$ & - & $100 \pm 12$ \\
\hline Tap water & $0.100^{c}$ & $0.101 \pm 0.013$ & - & $101 \pm 13$ \\
\hline Sea-water & $0.100^{c}$ & $0.102 \pm 0.005$ & - & $102 \pm 5$ \\
\hline
\end{tabular}

being retained. In such a case, an increase in the microcolumn length (use of more mercaptosilica) may solve the problem. The interference effect of $\mathrm{Cd}^{2+}$ is another example of this type, but because of the selectivity differences, $\mathrm{Cd}^{2+}$ does not cause any interference when its concentration is as low as $100 \mathrm{ng} \mathrm{ml}^{-1}$ (still 100 times the concentration of $\mathrm{Te}$ ) whereas this concentration for some other metal ions restricts the availability of mercapto functional sites for Te species, resulting in lower recoveries.

The behaviour of $\mathrm{Sn}^{2+}, \mathrm{Co}^{2+}, \mathrm{Ni}^{2+}$ and $\mathrm{Zn}^{2+}$ is very similar in that they do not cause a suppression in the Te signal when measured by HGAAS. However, they reduce the efficiency of the mercaptosilica microcolumn by occupying the available sites. Mercaptosilica retains $\mathrm{Sb}$ (III) also and if the concentration of $\mathrm{Sb}$ (III) is at least $500 \mathrm{ng} \mathrm{ml}^{-1}$ (500 times the concentration of $\mathrm{Te}$ ), interference occurs because of low recovery.

As a result of the interference studies, it can be stated that the use of mercaptosilica microcolumns provides a good preconcentration route for the determination of tellurium in a sample solution which does not contain elevated concentrations of selenite, $\mathrm{Ag}^{+}, \mathrm{Cu}^{2+}, \mathrm{Sn}^{4+}, \mathrm{Co}^{2+}, \mathrm{Ni}^{2+}$ and $\mathrm{Zn}^{2+}$.

\section{Method validation and analytical performance}

A Te concentration of $3.15 \pm 0.03 \mathrm{ng} \mathrm{ml}^{-1}$ was found in the reference solution (CRM, Trace Metals in Drinking Waters) and was compared with the certified value, $3 \mathrm{ng} \mathrm{ml}^{-1}$. The student's $t$-test was applied at the $95 \%$ confidence level and no difference was found between these two results. The composition of the certified drinking water sample used is given in Table 5. It should be noted that in the presence of fairly high concentrations of some major cations such as $\mathrm{Ca}^{2+}, \mathrm{Mg}^{2+}$, $\mathrm{K}^{+}$and $\mathrm{Na}^{+}$, no interference was observed. Some interferents which showed a suppressive effect over a wide range of concentrations (Table 4) did not interfere in this experiment; namely $\mathrm{Se}$ (IV or VI), $\mathrm{Sn}^{2+}, \mathrm{Bi}(\mathrm{III}), \mathrm{Co}^{2+}, \mathrm{Ni}^{2+}, \mathrm{Zn}^{2+}, \mathrm{Cu}^{2+}$ and $\mathrm{Ag}^{+}$. Therefore, these species do not interfere at concentrations below $100 \mathrm{ng} \mathrm{ml}^{-1}$, even when they are together; in other words, no cumulative effect was observed. On the other hand, $\mathrm{As}\left(\right.$ III or v), $\mathrm{Sb}$ (III or v), $\mathrm{Pb}^{2+}, \mathrm{Fe}^{3+}$ and $\mathrm{Cd}^{2+}$ were not expected to interfere; indeed they did not show any interference effect. This result demonstrated the applicability of the mercaptosilica microcolumn preconcentration methodology to the determination of $\mathrm{Te}$ in waters.

Another test of the efficiency of the microcolumn preconcentration scheme was performed through spike recovery experiments. The results are given in Table 6 . As can be seen, the enrichment procedure worked well for all three samples with spike recovery values around 100\%. These results indicated that the mercaptosilica microcolumn preconcentration scheme can be applied successfully to the determination of tellurium in various water samples. Quantitative recovery values, especially in sea-water, demonstrated the efficiency of mercaptosilica in rejecting the sea-water matrix ions, thus allowing the separation and preconcentration of tellurite in the presence of such a complex matrix. The accuracy of some
HGAAS measurements was tested by analysing the same samples by electrothermal AAS and almost identical results were obtained, as shown in Table 6.

\section{Conclusions}

It has been shown that mercapto-modified silica is an efficient preconcentration material for the determination of tellurium species in waters by HGAAS. When it is considered that various preconcentration methods which work efficiently with synthetic solutions are not readily applicable to real situations, mercapto-modified silica offers a real advantage in this respect; it can be employed in the separation and preconcentration of tellurium from several water samples including sea-water, a rather difficult matrix.

The methodology described is capable of speciation and matrix elimination in addition to preconcentration of tellurium from natural waters. While it has been demonstrated that the determination of Te(Iv) is feasible in both freshwater and seawater, further work is required for the validation of $\mathrm{Te}(\mathrm{vI})$ determination in sea-water.

The suitability of the microcolumn method to flow injection systems makes the development of on-line preconcentration systems for field use possible. Regarding the sample throughput, although the flow rate of $3 \mathrm{ml} \mathrm{min}-1$ would be limiting, parallel processing by use of multi-channel pumping is technically possible and desirable.

It is important to preserve the species as they are in the sample, during the period between sampling and analysis; this can be accomplished by using mercapto-modified silica columns. Therefore, these columns can have the function of preserving the original valency, as much as sampling and preconcentration, as regards Te(Iv).

Mercapto-silica microcolumns can also be used with more sensitive techniques such as ICP-MS with even lower volumes. In this case, elimination of the matrix and separation of the analyte species would be sufficient for quantification.

\section{Acknowledgements}

We acknowledge the financial support by the Middle East Technical University Research Fund through the funds AFP 9801-03-03 and AFP 99-01-03-06. Mürvet Volkan expresses her gratitude to Professor Alan G. Howard of the University of Southampton for his help and guidance during an academic visit to his laboratories where the first studies on the mercaptosilica were initiated. Ahmet E. Eroğlu is grateful to Professor Cameron W. McLeod for providing the opportunity to carry out research in the Centre for Analytical Sciences, University of Sheffield, on microcolumn methodologies and also for useful discussions.

\section{References}

1 T. Sadeh, in The Chemistry of Organic Selenium and Tellurium Compounds, ed. S. Patai, Wiley, Chichester, 1987, vol. 2, pp. 367376. 
2 A. D'Ulivo, Analyst, 1997, 122, 117R.

3 B. M. Yoon, S. C. Shim, H. C. Pyun and D. S. Lee, Anal. Sci., 1990, 6, 561.

4 K. Y. Chiou and O. K. Manuel, Anal. Chem., 1984, 56, 2721.

5 M. Q. Yu, G. Q. Liu and Q. Jin, Talanta, 1983, 30, 265.

6 M. O. Andreae, Anal. Chem., 1984, 56, 2064.

7 T. Ashino and K. Takada, Anal. Chim. Acta, 1995, 312, 157.

8 L. P. Greenland and E. Y. Campbell, Anal. Chim. Acta, 1976, 87, 323

9 D. S. Lee and J. M. Edmond, Nature (London), 1985, 313, 782.

10 Z. Li, N. Zhe-ming and S. Xiao-quan, Spectrochim. Acta, Part B, 1989, 44, 751 .

11 J. Dedina and D. L. Tsalev, Hydride Generation Atomic Absorption Spectrometry, Wiley, Chichester, 1995.

12 H. Matusiewicz and R. E. Sturgeon, Spectrochim. Acta, Part B, 1996, 51, 377

13 B. L. Gong, Y. M. Liu, Z. H. Li and T. Z. Lin, Anal. Chim. Acta, 1995, 304, 115.

14 H. Niskavaara and E. Kontas, Anal. Chim. Acta, 1990, 231, 273

15 C. Chung, E. Iwamoto, M. Yamamoto and Y. Yamamoto, Spectrochim. Acta, Part B, 1984, 39, 459.

16 O. Kujirai, M. Kohri, K. Yamada and H. Okochi, Anal. Sci., 1990, 6. 379 .

17 A. Morrow, G. Wiltshire and A. Hursthouse, At. Spectrosc., 1997, 18, 23.
18 H. Uggerud and W. Lund, J. Anal. At. Spectrom., 1995, 10, 405.

19 L. S. Zhang and S. M. Combs, J. Anal. At. Spectrom., 1996, 11 1043 .

20 G. E. M. Hall and J. C. Pelchat, J. Anal. At. Spectrom., 1997, 12, 97.

21 J. Feldmann, R. Grümping and A. V. Hirner, Fresenius' J. Anal. Chem., 1994, 350, 228.

22 A. G. Howard, M. Volkan and O. Y. Ataman, Analyst, 1987, 112 159.

23 M. Volkan, O. Y. Ataman and A. G. Howard, Analyst, 1987, 112, 1409.

24 A. G. Cox, I. G. Cook and C. W. McLeod, Analyst, 1985, 110, 331

25 M. Sperling, S. Xu and B. Welz, Anal. Chem., 1992, 64, 3101.

26 S. Dadfarnia and C. W. McLeod, Appl. Spectrosc., 1994, 48, 1331.

27 M. L. Mena, C. W. McLeod, P. Jones, A. Withers, V. Minganti, R. Capelli and Ph. Quevauviller, Fresenius' J. Anal. Chem., 1995, 351, 456.

28 G. F. Kirkbright and M. Taddia, Anal. Chim. Acta, 1978, 100, 145

29 B. Welz and M. Melcher, Analyst, 1984, 109, 569.

30 F. Inal, MS Thesis, Middle East Technical University, Ankara, 1989.

31 G. Göktürk, M. Delzendeh and M. Volkan, Spectrochim. Acta, Part B, 2000, 55, 1063 .

32 J. Dedina, Anal. Chem., 1982, 54, 2097 